OPEN ACCESS

Edited by:

Silvia Fraga,

University of Porto, Portugal

Reviewed by:

Carlos de Mestral,

Geneva University Hospitals

(HUG), Switzerland

Ana Henriques,

Institute of Public Health, University of

Porto, Portugal

${ }^{*}$ Correspondence:

Mary E. Northridge

mary.northridge@nyulangone.org

Specialty section:

This article was submitted to

Inequalities in Health

a section of the journal

Frontiers in Public Health

Received: 11 June 2019

Accepted: 12 November 2019

Published: 26 November 2019

Citation:

Gargano L, Mason MK and Northridge ME (2019) Advancing Oral Health Equity Through School-Based Oral Health Programs: An Ecological

Model and Review.

Front. Public Health 7:359

doi: 10.3389/fpubh.2019.00359

\section{Advancing Oral Health Equity Through School-Based Oral Health Programs: An Ecological Model and Review}

\author{
Lynn Gargano, Margaret K. Mason and Mary E. Northridge* \\ New York University (NYU) Langone Dental Medicine-Brooklyn, Hansjörg Wyss Department of Plastic Surgery, NYU School \\ of Medicine, Brooklyn, NY, United States
}

In the United States and elsewhere, children are more likely to have poor oral health if they are homeless, poor, and/or members of racial/ethnic minority and immigrant populations who have suboptimal access to oral health care. As a result, poor oral health serves as the primary marker of social inequality. Here, the authors posit that school-based oral health programs that aim to purposefully address determinants of health care access, health and well-being, and skills-based health education across multiple levels of influence (individual/population, interpersonal, community, and societal/policy) may be more effective in achieving oral health equity than programs that solely target a single outcome (screening, education) or operate only on the individual level. An ecological model is derived from previously published multilevel frameworks and the World Health Organization (WHO) concept of a health-promoting school. The extant literature is then examined for examples of evaluated school-based oral health programs, their locations and outcomes(s)/determinant(s) of interest, the levels of influence they target, and their effectiveness and equity attributes. The authors view school-based oral health programs as vehicles for advancing oral health equity, since vulnerable children often lack access to any preventive or treatment services absent on-site care provision at schools. At the same time, they are incapable of achieving sustainable results without attention to multiple levels of influence. Policy solutions that improve the nutritional quality of children's diets in schools and neighborhoods and engage alternative providers at all levels of influence may be both effective and equitable.

Keywords: school-based oral health programs, oral health equity, common risk factor approach, ecological model, federally qualified health centers, oral disease prevention, dental services, interventions to reduce inequalities

\section{INTRODUCTION}

Children who suffer from poor oral health are 12 times more likely to have restricted activity days than children with good oral health (1). Moreover, racial/ethnic minority children have been reported to experience 2 to 3 times poorer oral health compared to majority population children (2). Yet absent attention to the social determinants of health, school-based oral health education programs may not be accompanied by health gains (3), and when they do, they may actually exacerbate oral health inequalities (4). These sobering findings merit focused consideration of how 
schools may provide general and oral health care services on-site for vulnerable children, with the overall goal of advancing oral health equity and promoting social justice.

The particular focus of this review is on the underappreciated topic of oral health equity (5). Notwithstanding the provision of fluoride in its many forms (including through drinking water, fluoride varnish, and fluoridated toothpaste and mouthwash) (6) and improved detection and treatment modalities, dental caries remains a major public health challenge, affecting $60-90 \%$ of children worldwide (7). Indeed, while carious lesions are largely preventable-and even reversible-if detected in their early stages and when effective interventions are available, they remain the most common chronic health condition among school-aged children (8). If left untreated due to limited financial resources or lack of access to oral health care facilities, dental caries may cause pain and suffering, influence growth, development, and cognitive function, and lead to oral health problems in later life $(9,10)$. Since students with dental caries are more likely to miss school and perform poorly due to dental pain, improving their oral health is essential for enhancing their educational experience (11).

\section{An Ecological Model to Advance Oral Health Equity}

Ecological models posit that factors at multiple levels influence disparities in access to and quality of services (12). Interventions that address factors at multiple levels may be more effective than those that target a single level (13). Figure 1 originated in a health promotion framework by the senior author that considers dynamic social processes through which social and environmental inequalities - and associated health disparitiesare produced, reproduced, and potentially transformed $(14,15)$.

It was adapted from a multilevel model of influences on oral health and health disparities that highlighted family and social factors (16), also by the senior author, with important contributions from the World Health Organization (WHO) concept of a health promoting school toward realizing the goal of oral health equity $(17,18)$.

At the center of the ecological model are the 3 outcomes of interest potentially brought about by school-based oral health programs. First, school-based oral health programs may improve health care access, as schools are often the most efficient means of providing both preventive and treatment services for children $(17,18)$, especially for students from disadvantaged communities and families. Second, school-based oral health programs may improve general health and well-being, since oral health is fundamental to general health and has a well-documented impact on quality of life (18). Third, school-based oral health programs may improve skills-based health education, e.g., by enhancing understanding among students, teachers, and parents of factors that influence health, thus enabling them to make healthy choices and adopt healthy behaviors throughout their lives (17).

The next concentric circle in Figure 1 includes individual and interpersonal factors that affect these outcomes. Included therein are health behaviors, e.g., sugar consumption, as well as family and social support, e.g., influences on eating and oral health practices such as supervised toothbrushing with fluoride toothpaste, often constrained by socioeconomic conditions at home and school. For children, the attitudes, attributes, and knowledge of teachers and parents may be viewed as intermediary mechanisms through which societal and community influences affect their health and well-being (16). School-based oral health programs may achieve greater success if they take into account factors at the interpersonal levelincluding stressors on children and their families (homelessness) and potential buffers (parental involvement) - that may improve the outcomes of interest, rather than focus only individual level factors.

The last concentric circle in Figure 1 represents determinants of health- and education-related outcomes at the community level. Health promotion strategies that integrate elements of policy development and social and physical environmental factors may be yet more effective for oral disease prevention than isolated behavior-specific interventions $(19,20)$. In terms of the social environment, school-based oral health programs need to be cognizant of the social stigma associated with poor oral health, and address student and parental concerns regarding appearance as well as health (18). In terms of the physical environment, the available resources in given schools, notably space, may determine in part whether school-based oral health programs operate within a van or mobile bus, utilize portable equipment, or maintain fixed sites $(21,22)$.

Finally, the square in Figure 1 that contains the full model represents the societal level influences that school-based oral health programs must necessarily contend with and potentially help transform. These include macrosocial factors such as the lack of integrated medical and dental health care systems and the historical neglect of oral health within public health policies and programs. Instead, stakeholders at all levels would do well to tackle the underlying social determinants of oral and general health through the adoption of the common risk factor approach, emphasizing diet, hygiene, tobacco and alcohol use, stress, and trauma (23). Finally, inequalities in the distribution of wealth, education, and power as expressed through enduring health disparities reflect the universal social gradient and underscore the influence of economic and political determinants of oral and general health (24).

\section{SELECTED MODELS OF EVALUATED SCHOOL-BASED ORAL HEALTH PROGRAMS}

Models of evaluated school-based oral health programs were selected through a directed online search of the open access PubMed repository, using Figure $\mathbf{1}$ as the guide to identify search terms. It is important to emphasize that absent a rigorous evaluation, programs were not included in this analytic review. The literature search was not strictly linear as with a systematic review. Rather, apt examples of programs targeting single or multiple outcomes, and single or multiple levels of influence, were purposefully sought to illustrate the utility of Figure 1. It was also deemed critical to the authors to include programs 


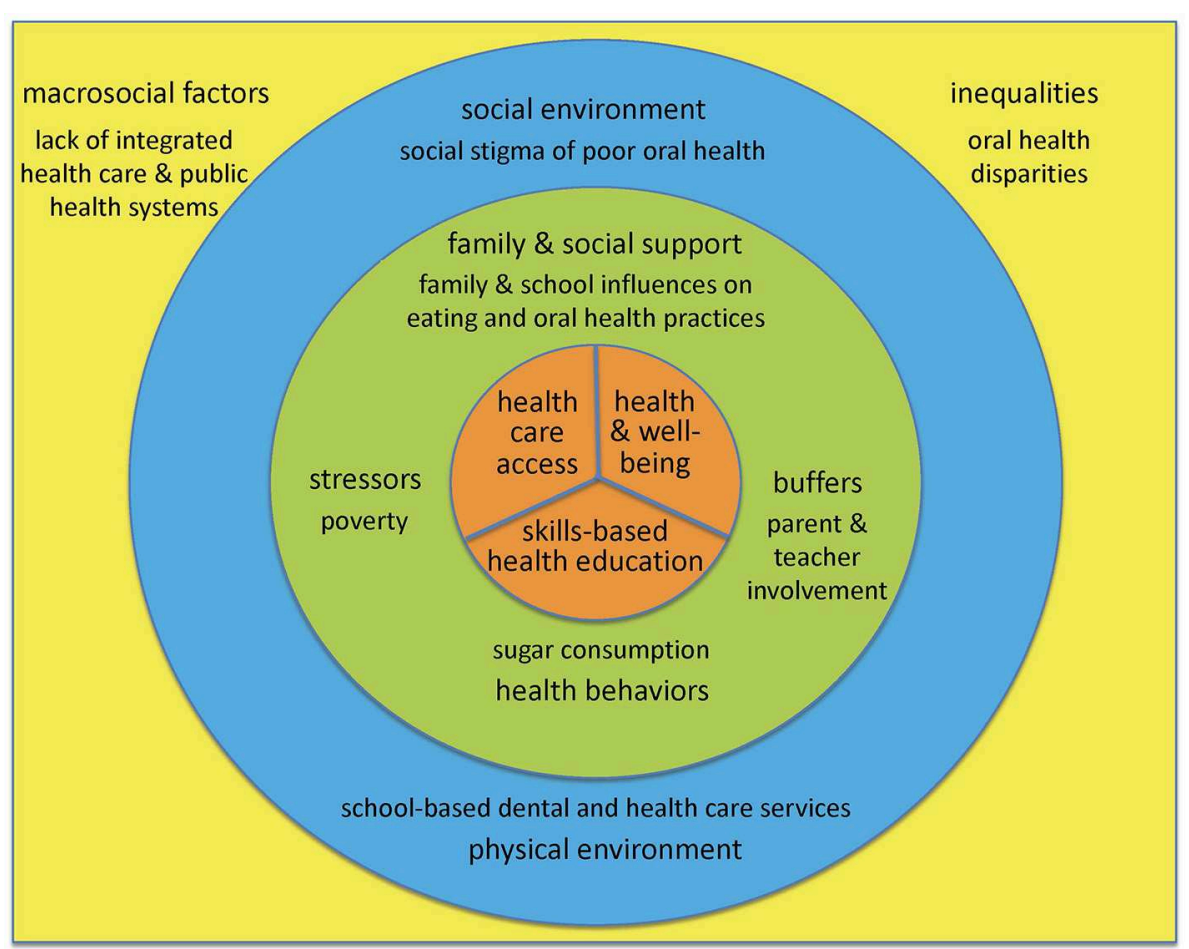

FIGURE 1 | An Ecological Model to Advance Oral Health Equity. An ecological model of influences on health care access, skills-based health education, and health and well-being brought about by school-based oral health programs, adapted from previous work by the senior author (14-16), with key contributions from the World Health Organization concept of a health promoting school $(17,18)$.

at various scales (local, regional, national) and geographies. The findings were organized first by outcome(s) and then by level(s) of influence targeted by the programs, and presented by beginning at the center of Figure $\mathbf{1}$ and moving outward to encompass increasingly higher levels of influence (Table 1).

For each factor in Figure 1, evaluated school-based oral health programs with the designated outcomes and determinants of interest at the individual/population, interpersonal, community, and societal/policy levels of influence were critiqued in terms of both their effectiveness and equity attributes.

\section{Screening to Determine Health and Well-Being}

At a minimum, school-based oral health programs might screen a population of children to determine their health and wellbeing. For example, the Ohio Department of Health conducted a statewide oral health and body mass index (BMI) screening survey among third grade children during the 2009-2010 school year (Table 1) (25). Of interest is that oral health and BMI were screened for together (25). As per the common risk factor approach (23), both dental caries and obesity may be prevented by focusing on the health behavior of lowering sugar consumption. Nonetheless, screening in isolation only provides data for monitoring the burden of disease, without improving the outcomes of interest or promoting oral health equity. Notably, schools with high student mobility and large school size had lower participation rates in this state-wide screening program (25).

\section{Skills-Based Health Education}

Certain school-based interventions focus on skills-based education, largely at the individual and interpersonal levels, as exemplified by the 4 programs presented in Table 1 (26-29). A multi-site cohort study conducted with children aged 10-11 years who attended 1 of 3 primary schools in the East Midlands, UK used a single interactive, evidence-based educational session lasting $\sim 60$ min delivered by a dental care professional (26). A 3year retrospective controlled clinical trial assessed the effect of a school-based oral health program on caries incidence of children aged 5-7 years from 2 public schools in Monte Sião, Brazil (27). A structured school-based oral health education program was implemented over 4 years in 6 primary schools in Ile-Ife, Nigeria (28), where a community-based education program complemented the school-based program by including pregnant women who attended antenatal clinics, providing general public education for parents to help dispel myths and misconceptions, and training teachers on the use of the curriculum (28). Finally, a school-based program using illustrative puzzles with a parental component comprised of a leaflet and brushing diary was designed for children aged 9 years in public primary schools in Tehran, Iran, where schools were randomly assigned to the intervention ( 4 boys' and 4 girls' schools) or control groups (2 boys' and 2 girls' schools) (29). 
TABLE 1 | Selected models of school-based oral health programs, along with their locations, outcome(s)/determinant(s) of interest, level(s) of influence, and effectiveness and equity attributes.

\begin{tabular}{|c|c|c|c|c|c|}
\hline References & Location & Outcome(s)/Determinant(s) & $\begin{array}{l}\text { Level(s) of } \\
\text { influence }\end{array}$ & Effectiveness attributes & Equity attributes \\
\hline
\end{tabular}

\section{Screening}

Detty (25)

$$
\text { Ohio, USA }
$$

Screening to determine measures of health and well-being [oral health and height/weight to determine body mass index (BMI)]

\section{Skills-based health education}

\begin{tabular}{|c|c|c|}
\hline $\begin{array}{l}\text { Blake et al. } \\
\text { (26) }\end{array}$ & $\begin{array}{l}\text { East } \\
\text { Midlands, } \\
\text { UK }\end{array}$ & $\begin{array}{l}\text { Skills-based health education (single } \\
\text { interactive evidence-based } \\
\text { educational session) }\end{array}$ \\
\hline $\begin{array}{l}\text { Jaime et al. } \\
\text { (27) }\end{array}$ & $\begin{array}{l}\text { Monte } \\
\text { Sião, Brazil }\end{array}$ & $\begin{array}{l}\text { Skills-based health education [(1) the } \\
\text { school dentist initially gave a lecture to } \\
\text { the children's parents; (2) the school } \\
\text { dentist then gave a short course to } \\
\text { the school staff; and (3) the trained } \\
\text { teachers subsequently delivered a } \\
6 \text {-module course to the students] }\end{array}$ \\
\hline $\begin{array}{l}\text { Esan et al. } \\
\text { (28) }\end{array}$ & $\begin{array}{l}\text { Ile-Ife, } \\
\text { Nigeria }\end{array}$ & $\begin{array}{l}\text { Skills-based health education } \\
\text { (school-based oral health education } \\
\text { curriculum for primary school } \\
\text { children, complemented by a } \\
\text { community-based educational } \\
\text { program targeted to } 3 \text { groups: } \\
\text { pregnant women, parents, and } \\
\text { teachers) }\end{array}$ \\
\hline $\begin{array}{l}\text { Saied- } \\
\text { Moallemi } \\
\text { et al. (29) }\end{array}$ & $\begin{array}{l}\text { Tehran, } \\
\text { Iran }\end{array}$ & $\begin{array}{l}\text { Skills-based health education (the } \\
\text { intervention consisted of illustrative } \\
\text { puzzles as learning tools for the } \\
\text { children and an oral health } \\
\text { educational leaflet and brushing diary } \\
\text { for the parents) }\end{array}$ \\
\hline
\end{tabular}

\section{School influences on oral health practices}

\begin{tabular}{|c|c|c|}
\hline $\begin{array}{l}\text { Lai et al. } \\
(30)\end{array}$ & $\begin{array}{l}\text { Taipei area, } \\
\text { Taiwan }\end{array}$ & $\begin{array}{l}\text { School influences on oral health } \\
\text { practices (meticulous instructions or } \\
\text { finger flossing the Bass method of } \\
\text { brushing of children originally aged } \\
10-11 \text { years, guided and monitored } \\
\text { by dentists and school nurses; } \\
\text { intensive oral health education by } \\
\text { school nurses and dental concepts } \\
\text { by dentists) }\end{array}$ \\
\hline
\end{tabular}

\section{School-based dental and health care services}

\begin{tabular}{|c|c|c|}
\hline $\begin{array}{l}\text { Larsen } \\
\text { et al. (31) }\end{array}$ & $\begin{array}{l}\text { New York, } \\
\text { NY, USA }\end{array}$ & $\begin{array}{l}\text { School-based dental and health care } \\
\text { services (largely diagnostic, } \\
\text { preventive, and restorative, with small } \\
\text { percentages of endodontics, } \\
\text { periodontics, surgery, and adjunctive } \\
\text { services delivered by dentists and } \\
\text { dental hygienists) }\end{array}$ \\
\hline $\begin{array}{l}\text { Carpino } \\
\text { et al. (32) }\end{array}$ & $\begin{array}{l}\text { Kansas } \\
\text { City, MO, } \\
\text { USA }\end{array}$ & $\begin{array}{l}\text { School-based dental and health care } \\
\text { services (examinations, oral health } \\
\text { instructions, prophylaxis, fluoride } \\
\text { applications, restorations, sealants, } \\
\text { emergency visits, extractions, and } \\
\text { endodontic treatment delivered by } \\
\text { dental and dental hygiene students) }\end{array}$ \\
\hline
\end{tabular}

Individual/ population

dividual, interpersonal

Individual, interpersonal interpersonal, community

Individual, interpersonal

During the 3-month school-based intervention, $60 \%$ of the children in the intervention group and $32 \%$ of the children in the control group achieved a healthy gingiva

Individual, interpersonal

After 10 years of follow-up, positive effects were found on the dental knowledge, oral hygiene habits, plaque scores, periodontal status, caries experience, and preventive dental visits of children in the intervention group

Individual, interpersonal, community

Individual, interpersonal, community
School-based clinics are more productive, efficient, and cost-effective than community-based clinics in providing dental care to underserved children, and perform more preventive services

\section{As the encounter intensity with a} dental or dental hygiene student increased, so too did the oral health of children (decrease in decay, increase in restorations, and reduction in referral urgency)
Lower participation rates were found with high student mobility and large school size

100\% participation rate was achieved, ensuring that all children received the intervention

Monte Sião has a Human Development Index of 0.811 (slightly higher than the Brazilian average of 0.792) and fluoridated water

The inability of control participants to purchase toothbrushes and other commodities for preventive oral self-care may have biased the findings

Girls experienced fewer barriers to dental care after the program and were more likely to achieve a healthy gingiva than boys

Parents' educational level did not differ between the intervention and control groups

Transportation issues, parent availability, and missed appointments are greatly reduced in school-based health clinics

Only $27.9 \%$ of eligible students participated in the program, the vast majority of whom qualified for the free or reduced lunch program 
TABLE 1 | Continued

\begin{tabular}{|c|c|c|c|c|c|}
\hline References & Location & Outcome(s)/Determinant(s) & $\begin{array}{l}\text { Level(s) of } \\
\text { influence }\end{array}$ & Effectiveness attributes & Equity attributes \\
\hline $\begin{array}{l}\text { Amalia } \\
\text { et al. (33) }\end{array}$ & $\begin{array}{l}\text { Province of } \\
\text { Yogyakarta, } \\
\text { island of } \\
\text { Java, } \\
\text { Indonesia }\end{array}$ & $\begin{array}{l}\text { School-based dental and health care } \\
\text { services (oral health screening } \\
\text { followed by oral health education in } \\
\text { classrooms at least twice a year; } \\
\text { classroom tooth brushing; children } \\
\text { identified with caries receive full } \\
\text { treatment upon referral; and all } \\
\text { teachers are trained in oral health } \\
\text { matters at least once a year) }\end{array}$ & $\begin{array}{l}\text { Individual, } \\
\text { interpersonal, } \\
\text { community }\end{array}$ & $\begin{array}{l}\text { Children participating in a poorly } \\
\text { performing program had a greater } \\
\text { likelihood of experiencing an oral } \\
\text { impact on their quality of life, but } \\
\text { difficulty with eating was higher } \\
(42.4 \%) \text { for good programs than for } \\
\text { poor programs (38.6\%) }\end{array}$ & $\begin{array}{l}\text { Living in a rural area and being a } \\
\text { girl were significantly associated } \\
\text { with a greater risk of having a } \\
\text { lower quality of life }\end{array}$ \\
\hline $\begin{array}{l}\text { Culler et al. } \\
\text { (34) }\end{array}$ & $\begin{array}{l}\text { Chelsea, } \\
\text { MA, USA }\end{array}$ & $\begin{array}{l}\text { School-based dental and health care } \\
\text { services [annual oral health } \\
\text { education, dental screening and } \\
\text { referral, and application of dental } \\
\text { sealants and fluoride varnish; }\end{array}$ & $\begin{array}{l}\text { Individual/ } \\
\text { population, } \\
\text { interpersonal, } \\
\text { community }\end{array}$ & $\begin{array}{l}\text { A greater percentage of Chelsea } \\
\text { students had untreated decay and } \\
\text { severe treatment need than students } \\
\text { statewide, but fewer Chelsea third } \\
\text { graders had severe treatment need }\end{array}$ & $\begin{array}{l}\text { There was no significant difference } \\
\text { in the percentage of Chelsea } \\
\text { students having severe treatment } \\
\text { need or dental sealants by income } \\
\text { level }\end{array}$ \\
\hline
\end{tabular}

\section{Multilevel interventions}

$\begin{array}{ll}\text { Muirhead } & \text { York } \\ \text { and } & \text { Region, } \\ \text { Lawrence } & \text { Ontario, } \\ \text { (35) } & \text { Canada }\end{array}$

$\begin{array}{ll}\text { Edasseri } & \text { Greater } \\ \text { et al. (19) } & \text { Montreal, } \\ & \text { Québec, } \\ & \text { Canada }\end{array}$

Ariga et al. Kuwait

(36)

Wolff et al. Grenada (37) preventive and restorative treatment (exams, cleanings, and fillings) provided at a centrally located, full-service, school-based dental clinic open year-round]

Multi-level intervention (the Healthy Schools recognition program is a voluntary program managed by the 72 Ontario school boards; existing or proposed health-related activities included healthy eating, physical activity, bullying prevention, personal safety and injury prevention, substance use and abuse, healthy growth and development and mental health activities)

Multi-level intervention (the QUALITY cohort recruited 630 white children aged 8-10 years at baseline from schools located within $75 \mathrm{~km}$ of 3 urban centers in the province of Québec; trained dentists performed the clinical oral health examination in a dental office during the hospital visit)

Multi-level intervention (School Oral Health Program, Kuwait, delivers oral health education, prevention, and treatment to 280,000 school-aged children; delivery of care is through a system of center- and school-based clinics and preventive mobile teams that deliver preventive services to children in schools without permanent dental clinics)

Multi-level intervention (toothbrushing in the classrooms, fluoride varnish applications, and placement of sealants; use of fluoride varnish in the hands of lay professionals provides a simple and safe caries-preventive therapy that can be utilized as a public health intervention through different providers when governmental organizations recognize that the benefits can far outweigh minimal risks)
Individual/ population, interpersonal, community, societal/policy

Individual/ population, interpersonal, community, societal/policy

Individual/ population, interpersonal, community, societal/policy

Individual/ population, interpersonal, community, societal/policy

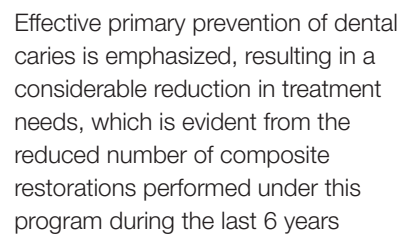

Effective primary prevention of dental caries is emphasized, resulting in a considerable reduction in treatment needs, which is evident from the reduced number of composite restorations performed under this program during the last 6 years

The results of the pre- and post-caries surveys indicated a reduction in caries incidence, yet a high volume, less labor-intensive sealant technique could not be effectively achieved when sealant retention was utilized as an outcome measure
Schools situated in poorer neighborhoods may benefit more from health promotion activities than schools situated in more affluent neighborhoods

Greatest protection against dental caries was found with both strong healthy eating environments inside the schools and favorable food environments around the schools

Prevention coverage (biannual application of fluoride varnish and the placement of pit and fissure sealants on newly erupted permanent molars and premolars) is close to $80 \%$.

Increased awareness of good oral health among children, teachers, parents, and local health care providers, and trained teachers and local providers to deliver the intervention toward improving its sustainability 
Overall, the 4 school-based health education programs reviewed were at most modestly effective in improving oral health-related knowledge and oral hygiene behaviors (26-29), mixed for health and well-being [no decrease in caries incidence achieved (27), but improvements in healthy gingiva found (29)], and health care access [fewer barriers to dental care (29)]. In terms of equity attributes, by conducting the programs in schools, most students received any associated benefits, except when the control participants or their families lacked the resources to purchase toothbrushes and other commodities for preventive oral self-care, or when boys and girls attended separate schools.

\section{School Influences on Oral Health Practices}

School influences on oral health practices are considered to be part of the interpersonal level in Figure 1 (a form of family and social support). From 1993-2005, the Taiwanese government.

Launched an intensive oral hygiene education program for schoolchildren originally aged 10-11 years (30) (Table 1). Approximately 10 children in each of 12 schools for a total of 120 children were selected to receive the intervention, which consisted of meticulous instructions on finger flossing and the Bass method of brushing delivered by dentists, a semester-long oral health education program delivered by school nurses, and dental concepts delivered by dentists. The age, gender, and school grade matched control group children carried out their oral hygiene procedures in their own ways, but still supervised by school nurses. In terms of effectiveness, after an average of 10 years of follow-up (range $=4-16$ years), positive effects on dental knowledge, oral hygiene habits, plaque scores, periodontal status, caries experience, and preventive dental visits were found in the intervention group (30). In terms of equity, no statistically significant difference in the parents' educational levels were found between the intervention and control groups.

\section{School-based Dental and Health Care Services}

Various models exist for providing preventive and restorative dental services for students in schools, part of the community level in Figure 1 that includes the physical environment (14, 15). Evaluations of their effectiveness have generally shown improvements in oral health among the children served, but limited coverage of student populations and services provided, as per the 4 evaluations reviewed in Table 1 (31-34). In the first evaluation, the productivity, types of services, and costeffectiveness of 4 dental clinics in schools were compared to 3 dental clinics in community-based health centers in New York City over a 12-month period (31). In the second evaluation, a repeated-measures design was used to longitudinally examine secondary data from participants at a dental clinic situated within a school-based health center and operated by the University of Missouri-Kansas City School of Dentistry (32). In the third evaluation, a cross-sectional survey was administered to students aged 12 years in 4 programs chosen to represent good and poor performance in urban and rural areas in Yogyakarta, Indonesia (33). The final evaluation was conducted of the Boston University/Chelsea Partnership Dental Program operating in Chelsea, MA, with a low-income and largely racial/ethnic minority population, by comparing participants' oral health to a Massachusetts state-wide oral health assessment (34).

In terms of effectiveness, schools act as an accessible location to provide preventive and responsive oral health care services to students (31-34). With regard to equity, however, schoolbased oral health programs on their own cannot overcome the challenges of the social determinants of oral health, including poverty (31-34), living in a rural location (33), or gender bias (33).

\section{Multilevel Interventions}

Only 4 studies found in the published literature examined multilevel interventions on children's oral health, and thus were better able to assess impacts on oral health equity (19, 35-37) (Table 1). An ecological study was conducted in the York Region of Ontario, Canada that compared schoollevel oral health outcomes in elementary schools participating in Ontario's Healthy Schools recognition program and nonparticipating schools, and examined the effect of neighborhood socioeconomic status on oral health outcomes (35). A second multilevel Canadian study examined oral health promoting school environments and dental caries in Québec children using data from a cohort study that recruited white children at risk of obesity and their families from Greater Montreal schools (19). Third, the School Oral Health Program, Kuwait, delivers skills-based educational activities to 280,000 public schoolchildren (including supervised toothbrushing), parents, and expectant mothers, along with prevention and treatment services delivered through a system of center- and school-based clinics and preventive mobile teams (36). Finally, the Smile Granada program was implemented nationally from 2010 to 2013 for children aged 6-8 and 14-15 years, consisting of a daily 2min toothbrushing routine using fluoridated toothpaste in every classroom, fluoride varnish applications 3-4 times per year, and glass ionomer sealants applied to the first permanent molars of children aged 6-8 years (37).

Thus, at both the regional $(19,35)$ and national levels $(36,37)$, school-based oral health programs have proven to be effective and equitable. Vulnerable children may lack access to any oral health preventive and treatment services without on-site care provision at schools. Still, they are incapable of achieving sustainable results without attention to multiple levels of influence.

\section{DISCUSSION}

The implications of this review for the oral health and wellbeing of vulnerable children are potentially transformative, since all levels of determinants in Figure 1 affect or are affected by school-based oral health programs. The included papers were selected to encompass several countries at different levels of socioeconomic development, and thus at different stages of demographic, epidemiologic, and nutritional transitions, in order to illustrate the utility of the ecological model in diverse contexts. Clearly, there are limitations to children learning about better oral hygiene and how to eat healthy, while vending machines and the menus at school cafeterias continue to promote unhealthy 
foods. Further, the harsh socioeconomic conditions of students at home may prevent them from achieving and maintaining proper oral health and nutritional eating behaviors. It is thus not surprising that homeless children suffer from higher obesity and dental caries rates than the US national childhood averages (38).

\section{Policy Solutions to Improve Nutrition and Oral Health}

Foremost among potential policy solutions are efforts focused on improving the nutritional quality of children's diets in schools and their surrounding neighborhoods $(19,35)$. Indeed, healthy eating environments may have effects beyond obesity reduction, benefitting children's oral health $(19,35)$. In addition to funding school-based oral health programs for caries reduction, resources ought to be directed to strategies that embrace the common risk factor and participatory approaches, with a special emphasis on disadvantaged schools and neighborhoods (19).

Another proposed policy solution is a universal preKindergarten to 8 th grade caries prevention program that is school-based and delivered twice a year (39). The bundle of preventive services might include: screening; silver diamine fluoride treatment of all caries, pits, and fissures; fluoride varnish; oral hygiene instruction; and provision of a toothbrush and fluoride toothpaste (39).

\section{Use Alternative Providers to Provide Oral Health Education, Promotion, and Care}

While dental hygienists $(40,41)$, including expanded care dental hygienists $(42,43)$, and mid-level providers such as dental therapists $(44,45)$ have met with successes and challenges in delivering school-based dental care, the universe of potential alternative providers is larger still. Teachers, school health nurses, and community health educators/workers $(37,46-48)$ are capable of reaching immigrant and other marginalized communities in need of improved health care access, health and well-being, and skills-based health education. For school-based oral health programs to be sustainable, it is important to create health teams with the active engagement of leaders at all levels, including health officials at the local, state, and national levels $(37,49)$.

\section{Expand the Capacity of Federally Qualified Health Centers (FQHCs) to Provide Oral Health Care Services}

FQHCs are community-based health centers that receive funds from the Health Resources and Services Administration (HRSA) Health Center Program to provide primary care services in underserved areas, regardless of the ability of individuals to pay for services, insurance coverage, or citizenship status $(50,51)$. They may also potentially fill an important role in increasing access to oral health care for vulnerable and underserved populations, including impoverished children and their families. For example, FQHCs are required to provide certain servicesincluding preventive, but not comprehensive, dental serviceseither in the clinic or by referral (52). The Institute of Medicine and the National Research Council recommend that HRSA expand the capacity of FQHCs to deliver essential oral health services by: supporting the use of a variety of oral health care professionals; enhancing financial incentives to attract and retain more oral health care professionals; providing guidance to implement best practices in management, operation, and efficiency; and assisting FQHCs in all states to operate programs outside of their physical facilities and leverage new systems to improve the oral health of the populations they serve (52). Notably, school-based oral health programs may either be operated by FQHCs (53) or partner with them for referral of student participants and their family members, so that everyone eventually secures a dental home.

\section{Research Priorities}

Finally, it will be important to critically evaluate what is working well and what is not, and rely on evidence-based strategies to achieve oral health equity through school-based oral health programs. Recommendations include: (1) engage community stakeholders in intervention development and implementation; (2) train teachers, parents, and community activists to counter myths regarding the effectiveness of fluoride in preventing and reversing carious lesions; (3) collect and report economic and cost-effectiveness data, which is especially important to policy makers; and (4) strengthen the scientific approaches used, including implementation science and community-based participatory research $(47,48)$.

\section{LIMITATIONS}

Figure 1 is an incomplete accounting of the determinants at multiple levels that move individuals/populations toward or away from oral health equity. Likewise, the model programs cited are illustrative of evaluated school-based oral health programs that target specific or multiple levels of influence and were available in PubMed at the time this article was written. Recent and other apt evaluated school-based oral health program reports have been omitted from this review, as the intent is to be illustrative of programs targeting single or multiple outcomes, and single or multiple levels of influence as per Figure 1, rather than comprehensive.

\section{CONCLUSION}

School-based oral health programs that target multiple levels of determinants of health care access, health and well-being, and skills-based health education may not only be more effective than those that target only one level, but they may also be more equitable in terms of health and education outcomes and more just for children throughout the social gradient. Policy solutions that improve the nutritional quality of children's diets in schools and their surrounding neighborhoods and engage alternative providers at all levels of influence are priorities toward realizing sustainable improvements in the health and well-being of disadvantaged children and their families. 


\section{AUTHOR CONTRIBUTIONS}

LG, MM, and MN each contributed to the conceptualization, research, critical analysis, and writing of the article, and take public responsibility for its content.

\section{FUNDING}

The School-based Oral Health Program at NYU Langone Dental Medicine was supported by the New York State Department of Health through the School-Based Dental Sealant Program (grant

\section{REFERENCES}

1. Shenoy RP, Sequeira PS. Effectiveness of a school dental education program in improving improving oral health knowledge and oral hygiene practices and status of 12- to 13-year-old school children. Indian J Dent Res. (2010) 21:253-9. doi: 10.4103/0970-9290.66652

2. Macnab AJ, Rozmus J, Benton D, Gagnon FA. 3-year results of a collaborative school-based oral health program in a remote First Nations community. Rural Remote Health. (2008) 8:882.

3. Redmond CA, Blinkhorn FA, Kay EJ, Davies RM, Worthington HV, Blinkhorn AS. A cluster randomized controlled trial testing the effectiveness of a schoolbased dental health education program for adolescents. J Public Health Dent. (1999) 59:12-7. doi: 10.1111/j.1752-7325.1999.tb03229.x

4. Qadri G, Alkilzy M, Franze M, Hoffmann W, Splieth C. School-based oral health education increases caries inequalities. Community Dent Health. (2018) 35:153-9. doi: 10.1922/CDH_4145Qadri07

5. Haque SE, Rahman M, Itsuko K, Mutahara M, Kayako S, Tsutsumi A, et al. Effect of a school-based oral health education in preventing untreated dental caries and increasing knowledge, attitude, and practices among adolescents in Bangladesh. BMC Oral Health. (2016) 16:44. doi: 10.1186/s12903-016-0202-3

6. Levin KA, Jones CM, Wight C, Valentine C, Topping GV, Naysmith R. Fluoride rinsing and dental health inequalities in 11-year-old children: an evaluation of a supervised school-based fluoride rinsing programme in Edinburgh. Community Dent Oral Epidemiol. (2009) 37:19-26. doi: 10.1111/j.1600-0528.2008.00445.x

7. Petersen PE, Bourgeois D, Ogawa H, Estupinan-Day S, Ndiaye C. The global burden of oral diseases and risks to oral health. Bull World Health Org. (2005) 83:661-9.

8. Kumar A, Cernigliaro D, Northridge ME, Wu Y, Troxel A, Cunha-Cruz J, et al. Caregiver acculturation and acceptance of silver diamine fluoride treatment for childhood caries treatment. BMC Oral Health. (2019) 19:228. doi: 10.1186/s12903-019-0915-1

9. Mouradian WE, Wehr E, Crall JJ. Disparities in children's oral health and access to dental care. JAMA. (2000) 284:2625-31. doi: 10.1001/jama.284.20.2625

10. Abanto J, Tsakos G, Paiva SM, Carvalho TS, Raggio DP, Bönecker M. Impact of dental caries and trauma on quality of life among 5- to 6-year-old children: perceptions of parents and children. Community Dent Oral Epidemiol. (2014) 42:385-94. doi: 10.1111/cdoe.12099

11. Jackson SL, Vann WF Jr, Kotch JB, Pahel BT, Lee JY. Impact of poor oral health on children's school attendance and performance. Am J Public Health. (2011) 101:1900-6. doi: 10.2105/AJPH.2010.200915

12. Purnell TS, Calhoun EA, Golden SH, Halladay JR, Krok-Schoen JL, Appelhans BM, et al. Achieving health equity: closing the gaps in health care disparities, interventions, and research. Health Aff. (2016) 35:1410-5. doi: 10.1377/hlthaff.2016.0158

13. Paskett E, Thompson B, Ammerman AS, Ortega AN, Marsteller J, Richardson D. Multilevel interventions to address health disparities show promise in improving population health. Health Aff. (2016) 35:1430-5. doi: $10.1377 /$ hlthaff.2015.1360

14. Northridge ME, Sclar ED, Biswas P. Sorting out the connections between the built environment and health: a conceptual framework for navigating
C32363GG), the Health Resources and Services Administration (HRSA) as part of the section 330 Public Health Service Act Health Center Program expanding services grant to Family Health Centers at NYU Langone, and the New York City Department of Health and Mental Hygiene through its rewards program for school-based dental services. Partial support for Dr. Northridge and/or her research was provided by grant U56DE027447 from the National Institute of Dental and Craniofacial Research (NIDCR), grant T93HP30391 from the Health Resources and Services Administration (HRSA), and grant P30CA016087 from the National Cancer Institute (NCI).

pathways and planning healthy cities. J Urban Health. (2003) 80:556-8. doi: $10.1093 /$ jurban/jtg064

15. Schulz A, Northridge ME. Social determinants of health: implications for environmental health promotion. Health Educ Behav. (2004) 31:455-71. doi: 10.1177/1090198104265598

16. Northridge ME, Schrimshaw EW, Estrada I, Greenblatt AP, Metcalf SS, Kunzel C. Intergenerational and social interventions to improve children's oral health. Dent Clin North Am. (2017) 61:533-48. doi: 10.1016/j.cden.2017.02.003

17. Petersen PE. The World Oral Health Report 2003: continuous improvement of oral health in the 21st century-the approach of the WHO Global Oral Health Programme. Community Dent. Oral Epidemiol. (2003) 31(Suppl. 1):323. doi: 10.1046/j..2003.com122.x

18. Kwan SYL, Petersen PE, Pine CM, Borutta A. Health-promoting schools: an opportunity for oral health promotion. Bull. World Health Org. (2005) 83:677-85. doi: 10.1016/B978-012373960-5.00527-X

19. Edasseri A, Barnett TA, Kâ K, Henderson M, Nicolau B. Oral healthpromoting school environments and dental caries in Québec children. Am J Prev Med. (2017) 53:697-704. doi: 10.1016/j.amepre.2017.07.005

20. Andrade J, Lotton J, Andrade J. Systematic review: frameworks used in school-based interventions, the impact on Hispanic children's obesityrelated outcomes. J Sch Health. (2018) 88:847-58. doi: 10.1111/josh. 12693

21. Moore J. Oral health in school-based health care clinics. J Mich Dent Assoc. (2013). 95:42, 44, 65.

22. Albert DA, McManus JM, Mitchell DA. Models for delivering school-based dental care. J Sch Health. (2005) 75:157-61. doi: 10.1111/j.1746-1561.2005.00016.x

23. Watt RG. Strategies and approaches in oral disease prevention and health promotion. Bull World Health Organ. (2005) 83:711-8.

24. Watt RG. From victim blaming to upstream action: tackling the social determinants of oral health inequalities. Community Dent Oral Epidemiol. (2007) 35:1-11. doi: 10.1111/j.1600-0528.2007.00348.x

25. Detty AM. School-based survey participation: oral health and BMI survey of Ohio third graders. Matern Child Health J. (2013) 17:1208-14. doi: 10.1007/s10995-012-1107-7

26. Blake H, Dawett B, Leighton P, Rose-Brady L, Deery C. Schoolbased educational intervention to improve children's oral health-related knowledge. Health Promot Pract. (2015) 16:571-82. doi: 10.1177/15248399145 60568

27. Jaime RA, Carvalho TS, Bonini GC, Imparato J, Mendes FM. Oral health education program on dental caries incidence for school children. J Clin Pediatr Dent. (2015) 39:277-83. doi: 10.17796/1053-4628-39.3.277

28. Esan A, Folayan MO, Egbetade GO, Oyedele TA. Effect of a school-based oral health education programme on use of recommended oral self-care for reducing the risk of caries by children in Nigeria. Int J Paediatr Dent. (2015) 25:282-90. doi: 10.1111/ipd.12143

29. Saied-Moallemi Z, Murtomaa H, Virtanen JI. Change in conceptions of Iranian pre-adolescents' oral health after a school-based programme: challenge for boys. Oral Health Prev Dent. (2014) 12:21-8. doi: 10.3290/j.ohpd.a31214

30. Lai H, Fann JC-Y, Yen AM-F, Chen L-S, Lai M-H, Chiu SY-H. Long-term effectiveness of school-based children oral hygiene program on oral health 
after 10-year follow-up. Community Dent. Oral Epidemiol. (2016) 44:209-15. doi: $10.1111 /$ cdoe. 12207

31. Larsen CD, Larsen MD, Handwerker LB, Kim MS, Rosenthal M. A comparison of urban school- and community-based dental clinics. J Sch Health. (2009) 79:116-22. doi: 10.1111/j.1746-1561.2008.00395.x

32. Carpino R, Walker MP, Liu Y, Simmer-Beck M. Assessing the effectiveness of a school-based dental clinic on the oral health of children who lack access to dental care: a program evaluation. J Sch Nurs. (2017) 33:181-8. doi: $10.1177 / 1059840516671784$

33. Amalia R, Schaub RM, Stewart RE, Widyanti N, Groothoff JW. Impact of school-based dental program performance on the oral health-related quality of life in children. J Investig Clin Dent. (2017) 8:e12179. doi: $10.1111 /$ jicd.12179

34. Culler CS, Kotelchuck M, Declercq E, Kuhlthau K, Jones K, Yoder KM. A school-based dental program evaluation: comparison to the Massachusetts Statewide Survey. J. Sch. Health. (2017) 87:784-9. doi: 10.1111/josh.12553

35. Muirhead VE, Lawrence HP. Exploring school oral health outcomes and neighbourhood factors in schools participating in Ontario's "Healthy Schools" recognition program. Can J Public Health. (2011).102:30-4. doi: 10.1007/BF03404873

36. Ariga J, Al-Mutawa S, Nazar H. School oral health program in Kuwait. Med Princ Pract. (2014) 23(Suppl. 1):43-6. doi: 10.1159/000356504

37. Wolff MS, Hill R, Wilson-Genderson M, Hirsch S, Dasanayake AP. Nationwide 2.5-year school-based public health intervention program designed to reduce the incidence of caries in children of Grenada. Caries Res. (2016) 50(Suppl. 1):68-77. doi: 10.1159/000439058

38. Chiu SH, Dimarco MA, Prokop JL. Childhood obesity and dental caries in homeless children. J Pediatr Health Care. (2013) 27:278-83. doi: 10.1016/j.pedhc.2011.11.007

39. Niederman R, Huang SS, Trescher AL, Listl S. Getting the incentives right: improving oral health equity with universal school-based caries prevention. Am J Public Health. (2017) 107:S50-5. doi: 10.2105/AJPH.2016.303614

40. Simmer-Beck M, Wellever A, Kelly P. Using registered dental hygienists to promote a school-based approach to dental public health. Am J Public Health. (2017) 107:S56-60. doi: 10.2105/AJPH.2017.303662

41. Conklin KV, Essex G, Rowe DJ. Factors influencing California dental hygienists' involvement in school-based oral health programs. J Dent Hyg. (2016) 90:234-43.

42. Simmer-Beck M, Walker M, Gadbury-Amyot C, Liu Y, Kelly P, Branson B. Effectiveness of an alternative dental workforce model on the oral health of low-income children in a school-based setting. Am J Public Health. (2015) 105:1763-9. doi: 10.2105/AJPH.2015.302714

43. Simmer-Beck M, Gadbury-Amyot CC, Ferris H, Voelker MA, Keselyak NT, Eplee $\mathrm{H}$, et al. Extending oral health care services to underserved children through a school-based collaboration: part 1: a descriptive overview. J Dent Hyg. (2011) 85:181-92.

44. Nash DA, Mathu-Muju KR, Friedman JW. Ensuring access to oral health care for children: school-based care by dental therapists-a commentary. J Sch Health. (2015) 85:659-62. doi: 10.1111/josh. 12297

45. Mathu-Muju KR, Friedman JW, Nash DA. Oral health care for children in countries using dental therapists in public, school-based programs, contrasted with that of the United States, using dentists in a private practice model. Am J Public Health. (2013) 103:e7-13. doi: 10.2105/AJPH.2013.3 01251

46. Conrado CA, Maciel SM, Oliveira MR. A school-based oral health educational program: the experience of Maringa- PR, Brazil. J Appl Oral Sci. (2004) 12:27-33. doi: 10.1590/S1678-775720040001 00006

47. Northridge ME, Kavathe R, Zanowiak J, Wyatt L, Singh H, Islam $\mathrm{N}$. Implementation and dissemination of the Sikh American Families Oral Health Promotion Program. Transl Behav Med. (2017) 7:435-43. doi: 10.1007/s13142-017-0466-4

48. Kavathe R, Islam N, Zanowiak J, Wyatt L, Singh H, Northridge ME. Building capacity in the Sikh Asian Indian community to lead participatory oral health projects. Prog. Community Health Partnersh. (2018) 12:3-14. doi: 10.1353/cpr.2018.0001

49. Bhardwaj VK, Sharma KR, Luthra RP, Jhingta P, Sharma D, Justa A Impact of school-based oral health education program on oral health of 12 and 15 years old school children. J Educ Health Promot. (2013) 2:33. doi: $10.4103 / 2277-9531.115820$

50. Health Resources \& Services Administration. Federally Qualified Health Centers. Eligibility. (2018). Available online at: https://www.hrsa.gov/ opa/eligibility-and-registration/health-centers/fqhc/index.html (accessed November 2, 2019).

51. Northridge ME, Kumar A, Kaur R. Disparities in access to oral health care. Annu Rev Public Health. (2020) 41.

52. Institute of Medicine and National Research Council. Improving Access to Oral Health Care for Vulnerable and Underserved Populations. Washington, DC: National Academies Press (2011).

53. Mason MK, Gargano L, Kumar A, Northridge ME. Implementing a patient-centered and cost-effective school-based oral health program. J School Health. (2019) 89:1024-7. doi: 10.1111/josh. 12842

Conflict of Interest: The authors declare that the research was conducted in the absence of any commercial or financial relationships that could be construed as a potential conflict of interest.

Copyright (c) 2019 Gargano, Mason and Northridge. This is an open-access article distributed under the terms of the Creative Commons Attribution License (CC BY). The use, distribution or reproduction in other forums is permitted, provided the original author(s) and the copyright owner(s) are credited and that the original publication in this journal is cited, in accordance with accepted academic practice. No use, distribution or reproduction is permitted which does not comply with these terms. 